to retain a little nourishment. There was no pain until October 1st, and then she was attacked with a severe cramp in the region of the sternal end of the last rib; next day extreme tenderness followed. This state of things lasted for five days, and vomiting again set in. The substance vomited was about one half a cupful of pus mixed with blood, very offensive. The next day pain and soreness began to diminish, and convalescence commenced, but she continued to expectorate rusty sputa for a number of days. No cough. I could detect no dullness or râles in any part of the lungs.

I would like to hear from some of the readers of the JourNaL of any like experience and result, and if any one would like a more minute description will gladly give it.

Freeport, Me., October 24, 1879.

J. G. Pinrce.

\title{
THE ADMISSION OF WOMEN TO THE MASSACHUSETTS MEDICAL SOCIETY.
}

Mr. Editor, - Having been one of those present at the October meeting of the councilors of the Massachusetts Medical Society, when the question of admitting women to examination by the censors for admission to membership, I must confess that I read with surprise the editorial in the Journal of the week. That a majority of forty-eight to thirty-two, one half of the whole number of the minority, one fifth of the aggregate vote, should be called small seemed to me either excessively unfair or very careless. Then the assumption of superiority pervading the tone of the article, announcing that if the majority did not reverse their action they would be disgraced, and asserting as an undoubted fact that the society at large would reverse the action of their council. Whereas the very report, in consequence of which this vote of the council was taken, shows seventy-one per cent. favorable to the admission of properly qualified women to full membership in the Massachusetts Medical Society, as shown by the replies from the society at large to a circular addressed to them by the Middlesex District Medical Society.

Then, again, with regard to the fears expressed for the endangered modesty of the Fellows, the writer of the article fails to perceive any danger of immodesty from conversation with females upon delicate subjects who are not practitioners of medicine, whereas it seems to me that the admission of women to the practice of medicine would tend to diminish the amount of conversation between those of different sexes upon such subjects.

Then, still again, as to the fear expressed of loss of scientific status, I do not see that the Medical Society of New York has suffered in its scientific reputation because it has admitted women to membership, and has been even presided over at its meetings by Mrs. Jacobi, who received a Boylston prize for a very valuable paper on menstruation, in competition with several other very able papers on the same subject. The medical societies of North Carolina and Rhode Island have also admitted women to membership, and $I$ have not yet seen this fact spoken of as any indication of their scientific decadence. That there should bę a difference of opinion upon this as upon almost every other new subject is to be expected, but it does not seem decorous in a medical journal to set up its opinion as so very conclusive in speaking of the action of a large majority of the chosen councilors of the medical society of the State.

S. Caвot.

[The above is perhaps a fair sample of the sort of argument to which we are accustomed from the woman side of the question; as to the charge of discourtesy in our editorial, we think we can safely leave the two articles to the judgment of our readers. It will be observed, however, that our argument has hardly been touched upon. - ED.] 